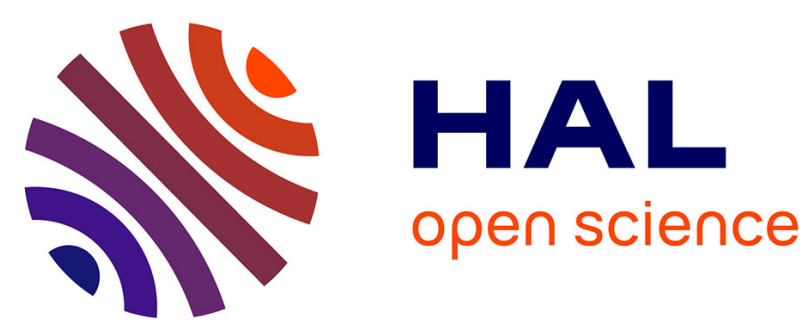

\title{
Sonic Hedgehog pathway activation is associated with resistance to platinum-based chemotherapy in advanced non-small cell lung carcinoma
}

Etienne Giroux Leprieur, Thibault Vieira, Martine Antoine, Nathalie Rozensztajn, Nathalie Rabbe, Anne-Marie Ruppert, Armelle Lavole, Jacques Cadranel, Marie Wislez

\section{To cite this version:}

Etienne Giroux Leprieur, Thibault Vieira, Martine Antoine, Nathalie Rozensztajn, Nathalie Rabbe, et al.. Sonic Hedgehog pathway activation is associated with resistance to platinum-based chemotherapy in advanced non-small cell lung carcinoma. Clinical Lung Cancer, 2015, 17 (4), pp.301-308. 10.1016/j.cllc.2015.12.007 . hal-01251414

\section{HAL Id: hal-01251414 https://hal.sorbonne-universite.fr/hal-01251414}

Submitted on 6 Jan 2016

HAL is a multi-disciplinary open access archive for the deposit and dissemination of scientific research documents, whether they are published or not. The documents may come from teaching and research institutions in France or abroad, or from public or private research centers.
L'archive ouverte pluridisciplinaire HAL, est destinée au dépôt et à la diffusion de documents scientifiques de niveau recherche, publiés ou non, émanant des établissements d'enseignement et de recherche français ou étrangers, des laboratoires publics ou privés. 


\section{Sonic Hedgehog pathway activation is associated with resistance to platinum-} based chemotherapy in advanced non-small cell lung carcinoma

Short Title: Shh and chemoresistance in non-small cell lung cancer

Etienne Giroux Leprieur ${ }^{\mathrm{a}, \mathrm{b}^{*}}$, Thibault Vieira ${ }^{\mathrm{a}, \mathrm{c}^{*}}$, Martine Antoine ${ }^{\mathrm{a}, \mathrm{d}}$, Nathalie Rozensztajn ${ }^{c}$, Nathalie Rabbe ${ }^{a, c}$, Anne-Marie Ruppert ${ }^{a, c}$, Armelle Lavole ${ }^{c}$, Jacques Cadranel ${ }^{\mathrm{a}, \mathrm{c}}$, Marie Wislez ${ }^{\mathrm{a}, \mathrm{c}}$.

a. Sorbonne Universités, UPMC Univ Paris 06, GRC n04, Theranoscan, F75252, Paris

b. AP-HP, Hôpital Ambroise Paré, Service de Pneumologie et Oncologie Thoracique, EA 4340 BCOH Univ Versailles Saint Quentin en Yvelines, 92100 Boulogne-Billancourt

c. AP-HP, Hôpital Tenon, Service de Pneumologie, F-75970, Paris

d. AP-HP, Hôpital Tenon, Service d'Anatomie Pathologique, F-75970, Paris

*These authors contributed equally

Corresponding author: Prof. Marie Wislez; AP-HP, Hôpital Tenon, Service de Pneumologie, F-75970, Paris. Tel: +33 (0)156016838. Fax: +33 (0)156017248. Email: marie.wislez@tnn.aphp.fr 


\section{Abstract}

Introduction: Chemoresistance is a major challenge in the treatment of advanced non-small cell lung cancer (NSCLC). As the Sonic Hedgehog (Shh) pathway is reactivated in NSCLC, we investigated an association between chemoresistance and Shh activation.

Materials and Methods: From a cohort of 178 patients with advanced NSCLC treated with platinum-based chemotherapy as first-line treatment, we selected all surgical tumor samples at diagnosis $(n=36)$. Shh activation was evaluated through Gli1 and Gli2 expression by immunohistochemistry (IHC) (quantitative score). In vitro treatment studies with cisplatin, vismodegib (Shh-pathway inhibitor) or both were performed on NSCLC cell lines (H322 and A549) and on primary cultures from patients with sarcomatoid carcinoma $(n=4)$.

Results: Twelve patients were refractory to chemotherapy (r-patients, 33.3\%) and 24 had controlled disease (c-patients). Gli1 expression did not differ between the $r$ - and c-patients $(p=0.35)$. Gli2 expression was more often positive in the r-patients $(41.7 \%$ versus $8.3 \%, p=0.02$ ). Progression-free survival (PFS) and overall survival $(O S)$ in patients with Gli2-positive score were 2.1 and 8.0 months, respectively, versus 6.7 and 18.0 months in patients with Gli2-negative score $(p=0.03 ; p=0.002)$. In multivariate analysis, Gli2 score was independently correlated with PFS (hazard ratio $[H R]=2.64 ; 95 \%$ confidence interval $[\mathrm{Cl}]: 1.05-6.63 ; \mathrm{p}=0.04)$ and $\mathrm{OS}(\mathrm{HR}=4.36 ; 95 \%$ Cl: 1.67-11.36; $p=0.003)$. The sarcomatoid carcinoma cell lines were more resistant to cisplatin than the $\mathrm{H} 838$ and A549 cell lines. The cisplatin - vismodegib combination displayed a synergistic cytotoxic effect in the most chemoresistant cells in vitro.

Conclusion: The Shh pathway is associated with resistance to platinum-based chemotherapy in NSCLC.

Key words: non-small cell carcinoma; chemoresistance; Sonic Hedgehog; Gli; sarcomatoid carcinoma 


\section{Micro-abstract}

$30 \%$ of patients with advanced NSCLC are refractory to platinum- based chemotherapy

- We investigated the role of the Sonic Hedgehog (Shh)pathway in these rpatients

- $\quad$ R-patients had a higher Gli2 expression than other patients

Gli2 expression was independently correlated with PFS and OS

Shh pathway inhibition had a synergistic effect in vitro with cisplatin 


\section{Introduction}

Despite the progress made in oncogenic driver identification, most advanced nonsmall cell lung cancers (NSCLCs) are treated with first-line cytotoxic platinum-based chemotherapy. According to the majority of randomized Phase III trials, approximately $25 \%$ to $30 \%$ of patients exhibit early disease progression under chemotherapy and are called refractory patients (r-patients) [1-9]. We previously described the characteristics of $r$-patients [10]. The only factor independently correlated to early progression was the sarcomatoid subtype. In another study, nearly $70 \%$ of patients with advanced sarcomatoid carcinoma exhibited early progression with chemotherapy [11]. Numerous predictive factors of resistance to platinum-based chemotherapy have been extensively studied in NSCLC, yet the majority involved early-stage NSCLC treated with surgery due to the availability of tumor tissue. ERCC1 (Excision Repair Cross-Complementary group 1) is a protein involved in DNA repair. Its predictive role of adjuvant chemotherapy benefit in early-stage NSCLC has already been demonstrated [12], although its impact on chemoresistance in advanced-stage disease is more debatable [13,14]. A Phase II trial has demonstrated the feasibility of a personalized adjuvant treatment according to epidermal growth factor receptor (EGFR) and ERCC1 status [15]. However, the antibody used for ERCC1 expression in immunohistochemistry (IHC) is not reliable, and ERCC1 expression testing in IHC is no longer recommended [16]. BRCA1 (Breast Cancer 1) is another protein involved in DNA repair. Despite encouraging preliminary data on its impact on chemoresistance prediction in advanced-stage NSCLC [17,18], a recent phase III trial testing customized chemotherapy according to BRCA1 level was reported as negative [19]. There is therefore an urgent need to validate new predictive markers. 
The role of cancer stem cells (CSCs) in chemoresistance has previously been suggested [20]. CSCs constitute a small undifferentiated tumor cell contingent, chemoresistant and responsible for cancer relapse and metastatic spreading. Some specific pathways are overexpressed in CSCs, such as the Sonic Hedgehog (Shh) pathway. Shh pathway overexpression has been demonstrated in small-cell lung cancer (SCLC) and NSCLC [21-25]. The final downstream factor in the Shh pathway is the Gli protein family, primarily Gli1 and Gli2, responsible for gene transcription. In this study, we analyzed the role of Shh pathway activation in advanced NSCLC refractory to first-line platinum-based chemotherapy.

\section{Patients and methods}

\subsection{Patients and tumor samples}

We retrospectively reviewed all consecutive patients treated in our department with platinum-based doublet chemotherapy as first-line therapy for non-irradiable Stage Illb - IV NSCLC, according to the $6^{\text {th }}$ TNM classification by the International Association for the Study of Lung Cancer (IASLC). In order to get enough material for biomarker analysis, patients with surgical samples were selected from our hospital's tumor bank (Tumorothèque des Hôpitaux Universitaires de l'Est Parisien [HUEP], AP-HP, Tenon Hospital). All samples were collected at diagnosis before any chemotherapy. The inclusion period ran from January 2003 to December 2006. Demographic, histological, and treatment data were recorded. All patients were evaluated for tumor response after three cycles of treatment by means of clinical examination, chest X-ray, and chest and upper-abdomen computed tomography scan, conducted by dedicated radiologists specialized in thoracic oncology. At that 
time, the patients were classified as having early progressive disease (r-patients) or controlled disease (c-patients, i.e., complete or partial response or stable disease) according to the World Health Organization (WHO) criteria. All tumor samples were collected and centrally reviewed by a pathologist specialized in thoracic malignancies (M.A). The pathologist was blinded to the patients' clinical outcomes. The histological type was determined according to the latest IASLC WHO classification [26].

\subsection{Immunohistochemistry (IHC)}

We used the anti-rabbit Gli1 (sc-20687, 1:75, Santa Cruz) and anti-rabbit Gli2 (ab26056, 1:200, Abcam, UK) antibodies for IHC, according to standard protocol. IHC nuclear intensity staining was scored from 0 (no staining) to 3 (strong nuclear staining). Scores were considered positive if $\geq 25 \%$ of the tumor cells exhibited a staining intensity $\geq 2$ [27]. All the $\mathrm{IHC}$ staining results were validated by a pathologist specialized in thoracic malignancies (M.A).

\subsection{Molecular biomarkers}

EGFR (exons 19, 20, and 21) and Kirsten Ras (KRAS) (exon 2) mutations were investigated by direct sequencing. DNA was extracted using the QIAmp DNA mini-kit (Qiagen, Netherlands) from paraffin-embedded tissue, according to the manufacturer's instructions. All mutations were confirmed by a second polymerase chain reaction (PCR) analysis. DNA samples were tested twice for amplification to definitively conclude them as being non-amplifiable. 


\section{ACCEPTED MANUSCRIPT}

The anaplastic lymphoma kinase $(A L K)$-fusion transcript was investigated by $\mathrm{IHC}$ on 4- $\mu \mathrm{M}$ slides from paraffin-embedded tissue using a monoclonal mouse antibody (5A4) (Abcam, UK) on a Benchmark system (Ventana Medical System, USA), according to the manufacturer's instructions [28]. Staining was quantified as the percentage of positive cells ( $0-100 \%$ ) with an intensity ranging from 0 (no staining) to 3 (strong staining). A $10 \%$ positivity of cells with an intensity $\geq 2$ defined positive staining, as reported by Yi et al. [29].

\subsection{Cultures and MTT assays}

Primary cultures were obtained from tumors from four sarcomatoid carcinoma patients and cultured in a mix of Iscove Modified Dulbecco's Medium (IMDM, Lonza Group Ltd., Switzerland) and Bronchial Epithelial Cell Basal Medium (BEBM, Lonza) (2:1), with $10 \%$ fetal bovine serum (FBS) and Bronchial Epithelial Cell Growth Medium (BEGM, Lonza). A549 and H322 cell lines were obtained from the American Type Culture Collection (ATCC) and cultured in Roswell Park Memorial Institute (RPMI) culture medium, with 10\% FBS. At 100\% confluence, the cells were trypsinized and seeded in 96-well plates (5000 cells/well) with RPMI $+10 \%$ FBS. On Day 1 (d1), the cells were treated with cisplatin (Sigma Aldrich, USA), vismodegib (SelleckChem, USA), or a cisplatin - vismodegib combination at $20 \mu \mathrm{M}$ concentration for each drug, according to the dose effect observations of preliminary studies. The negative controls were given diluent alone (sodium chloride $(\mathrm{NaCl})$ solution or dimethyl sulfoxide (DMSO)). On d2, WST-1 proliferation assay (Roche, Germany) was conducted in each well and optic density was assessed 2 hours later (450nm) by means of spectrophotometer. Density was normalized according to controls (DMSO 
or $\mathrm{NaCl}$ solution). All experiments were conducted in quadruplicate and repeated three times each.

\subsection{Ethical considerations}

Each patient signed a research-approval form according to national guidelines, authorizing the use of their tumor samples for research. The samples were collected according to French legislation adhering to medical ethical laws. Approval of an ethic comitee was not necessary as it was a non-interventional translational study. All samples were selected from our hospital's tumor bank (Tumorothèque des Hôpitaux Universitaires de l'Est Parisien [HUEP], AP-HP, Tenon Hospital).

\subsection{Statistical analyses}

Comparisons of categorical variables between the r- and c-patients were performed using the chi-squared test, whereas comparisons between continuous variables were conducted using the Mann-Whitney test. Continuous variables were expressed as mean \pm standard deviation (SD) for normal distributions or median + interquartile range (IQR) for non-normal distributions. PFS and survival were evaluated using the Kaplan-Meyer method (log-rank test), and were expressed as median \pm IQR. The

censoring date was 07/02/2014. Multivariate analysis was performed using a logistical regression model and included all variables that produced a $p$-value $<0.25$ in the univariate comparison between $\mathrm{r}$ - and c-patients. The combinatorial effects of treatments were quantified using the Chou-Talalay method to obtain the Combination Index $(\mathrm{Cl})$, where $\mathrm{Cl}<1,=1$, and $>1$ represented synergism, additive effect, and 
antagonism, respectively [30]. The correlation between the IC50 of cisplatin and the Cl was assessed using Spearman's rank-order correlation test. P-values $<0.05$ were considered statistically significant. Statistical analyses were carried out using Xlstat 2014 software (Addinsoft@), France).

\section{Results}

\section{1. r-patients exhibited higher Gli2 expression than c-patients}

A total of 256 consecutive patients were diagnosed with Stage IIIb or IV NSCLC between 2003 and 2006. Eleven patients were not treated due to their poor performance status ( $\mathrm{PS}=3$ or 4 ). Of the 245 treated patients, 178 received platinumbased doublet chemotherapy as first-line treatment. Data on this cohort has already been published [11]. Of these 178 patients, 36 had surgical pathological samples available for analysis. The demographic data has been summarized in Table 1 . The gender $(p=0.78)$, smoker status $(p=0.53)$, and tumor histological types $(p=0.36)$ of these patients were similar to those of the 178 patients of the initial cohort. In contrast, these 36 patients were younger than those from the entire cohort (mean: 53.4 years \pm 10.2 versus 59.1 years $\pm 9.9, p=0.02$ ). On the 36 patients, 12 were $r$ patients (33.3\%) and 24 c-patients (66.7\%). The r-patients were more often female (66.7\% of $r$-patients versus $20.8 \%$ of c-patients, $p=0.01)$. Gli1 and Gli2 were expressed in tumor cells and there was no expression in normal lung tissue. IHC for Gli1 revealed 11 samples to exhibit positive Gli1 score (31.4\%) and 24 negative score (68.6\%) (one sample was not contributive). Among the positive samples, the median percentage of positive tumor cells for Gli1 was $80 \%$ (IQR: $50-90 \%$ ). IHC for Gli2 revealed seven samples to have positive Gli2 score (19.4\%) and 29 negative score $(80.6 \%)$ (Figure $1 \mathrm{~A}$ and $\mathrm{B}$ ). Among the positive samples, the median 
percentage of positive tumor cells for Gli2 was 40\% (IQR: 12.5-45\%). The Gli1 positive score did not differ between r-patients and c-patients $(41.7 \%$ versus $26.1 \%$, respectively; $p=0.35$ ) (Figure $1 \mathrm{C}$ ). Gli2 positive score was more frequent in the $r$ patients than in c-patients ( $41.7 \%$ versus $8.3 \%$, respectively; $p=0.02)$ (Figure 1D). The characteristics of Gli2-positive patients have been summarized in Table 2. Gli2positive score was more frequent in the Stage IV than IIlb patients: of the seven Gli2positive samples, six (85.7\%) were Stage IV and one (14.3\%) was Stage IIlb, whereas of the 29 Gli2-negative samples, 12 (41.4\%) were Stage IV and 17 (58.6\%) Stage IIlb $(p=0.04)$. No difference was observed concerning histological subtypes for Gli2 staining. There was a good concordance between Gli1 and Gli2-scores, as 71.4\% of the Gli2-positive samples were also Gli1-positive.

3.2. Patients with Gli2-positive tumors had shorter PFS and shorter OS compared to c-patients

Gli1-positive score had no impact on PFS or OS (Figure 2A and B). Gli2-positive score was associated with both shorter PFS and OS (Figure 2C and D). Patients with Gli2-positive score had a median PFS of 2.1 months (IQR: 1.8-5.2), whereas those with Gli2-negative score had a median PFS of 6.7 months (IQR: 4.2-12.1) $(p=0.03)$. Patients with Gli2-positive score had a median OS of 8.0 months (IQR: 4.5-9.7), whereas those with Gli2-negative score had a median OS of 18.0 months (IQR: 11.227.0). In multivariate analysis on PFS (Table 3), the significant variables consisted of sarcomatoid histological subtype (HR=14.29; 95\% Cl: 2.30-83.33; $p=0.004)$ and Gli2positive score (HR=2.64; 95\% Cl: 1.05-6.63; $\mathrm{p}=0.04)$. In multivariate analysis on OS (Table 4), the only significant variable was Gli2-positive score $(\mathrm{HR}=4.36 ; 95 \% \mathrm{Cl}$ : 
1.67-11.36; $p=0.003)$. In order to confirm the prognostic and predictive impact of Gli2 expression, independently of the cut-off value, we analyzed the staining intensity as a continuous variable in multivariate analysis, revealing Gli2 expression to still constitute an independent factor of PFS (HR=1.75; 95\% Cl: 1.15-2.69; $p=0.01)$ and OS (HR=1.81; $95 \% \mathrm{Cl}: 1.18-2.77 ; \mathrm{p}=0.007)$.

3.3. Inhibition of the Shh pathway sensitized chemoresistant CBNPC cells in vitro

We used NSCLC cell lines (H322 and AA549) and primary cell lines of sarcomatoid carcinomas $(n=4)$, treated in vitro by cisplatin. As expected, the H322 and A549 cell lines were more chemosensitive (IC50 of $27 \mu \mathrm{M}$ and $56 \mu \mathrm{M}$, respectively), than the four sarcomatoid primary cell cultures (IC50 of $67 \mu \mathrm{M}, 75 \mu \mathrm{M}, 100 \mu \mathrm{M}$, and $500 \mu \mathrm{M}$ ). Inhibition of Shh pathway, using smoothened (SMO) receptor inhibitor vismodegib, induced minimal cytotoxic effect on the six different cell lines. As shown in Figure 3A, concomitant treatment with cisplatin and vismodegib induced a synergistic cytotoxic effect in the three most resistant sarcomatoid primary cultures, demonstrated by the resulting $\mathrm{Cl}<1$, and had no synergistic effect on either the most chemosensitive sarcomatoid primary culture (with the IC50 for cisplatin found to be similar to IC50 of A549) or the two NSCLC cell lines. There was also a significant correlation between the IC50 of cisplatin and the $\mathrm{Cl}$, suggesting that vismodegib benefit is higher in the most chemoresistant cells (Figure 3B). 


\section{Discussion}

We found that the Shh pathway was activated in advanced NSCLC, with expression of Gli1 and Gli2 in $31.4 \%$ and $41.7 \%$ of tumor samples, respectively. Moreover, a Gli2-positive score was associated with chemoresistance. R-patients more often exhibited a Gli2-positive score compared to the c-patients, and a Gli2-positive score was found to be an independent factor of poor PFS and poor OS in multivariate analysis. In vitro studies confirmed that the inhibition of the Shh pathway had a synergistic effect with cisplatin on proliferation inhibition, especially in the most chemoresistant cells.

The Shh pathway has been shown to be overexpressed in numerous solid tumors, such as NSCLC [23-25,31]. Several studies have shown a correlation between Shh activation and chemoresistance [32-34]. Interestingly, we found that the Gli-2 positive samples were more often Stage IV, indicative of the role played by Shh pathway activation in tumor dissemination. Yue et al. also demonstrated a correlation between Shh activation and epithelial-mesenchymal transition in squamous-cell lung carcinomas [35].

We found that Gli2 has an impact on prognosis in advanced NSCLC. Previous studies have suggested that Gli1 expression has a prognostic capacity in early-stage NSCLC. While Yue et al. found that Gli1 expression was inversely correlated with disease-free survival in early-stage squamous-cell carcinoma [35], they did not test Gli2 expression in this study. Little is known about the transcriptional activity differences between Gli1 and Gli2, Both Gli1 and Gli2 are known to have the same promoter-binding site [36], yet Gli1 is expressed secondarily, induced by Gli2 [37,38]. Nevertheless, these findings result from studies conducted in developmental steps or 
in normal tissue, not in solid tumors. The majority of NSCLC studies have used Gli1, not Gli2, as the surrogate marker of the Shh pathway. As we found that Gli2, had an impact on PFS or OS, and not Gli1, some differences may exist between these two proteins in NSCLC, and further studies are therefore required.

We found that the inhibition of the Shh pathway by vismodegib sensitized tumor cells to cisplatin treatment. Tian et al. published similar results, with lower cell survival rates in vitro with combined vismodegib and cisplatin therapy compared to using either alone in HCC cell line [39], yet no synergistic score was used. Other studies have already reported vismodegib to be efficient in cisplatin-resistant lung-cancer cells $[38,39]$, although these results were based on a single NSCLC cell line (H1399 or A549). Interestingly, the same results were found in malignant pleural mesothelioma, with a synergistic effect observed with vismodegib and pemetrexed [40]. Vismodegib has been tested in a phase II trial in unselected advanced small-cell lung carcinoma, in addition with platinum - etoposide chemotherapy in first line, with negative results (Eastern Cooperative Oncology Group ECOG-1508 trial) [41]. However, no published data are available to date with vismodegib in advanced NSCLC. Shh inhibition in NSCLC with vismodegib is challenging, because of possible non-canonical Gli activation mechanisms. However, some papers have suggested that, in NSCLC, the canonical Shh activation pathway, through Smo activation, is the predominant mechanism [35].

Our study displayed several limitations. First, this was a retrospective study, involving a small number of patients. In addition, we only studied samples from surgical procedures. However, this cohort was found to be representative of the general population, as there was no statistical difference concerning the demographic data (gender, smoker status, or histological type) between this surgical cohort and the 
entire cohort, except for age. The patients who underwent surgery were younger than the patients from the general cohort, probably due to a selection bias for surgery. Finally, further experiments are needed to validate the Gli2 IHC score and its prognosis impact in a larger prospective validation cohort, including small-size biopsies.

In conclusion, Shh pathway activation appears to play a critical role in terms of chemoresistance and prognosis. Furthermore, the benefits of Shh pathway inhibition are even greater in chemoresistant NSCLC. Targeted Shh therapies should now be investigated and evaluated through clinical studies in NSCLC r-patients.

\section{Clinical practice points}

Chemoresistance is a major challenge in the treatment of advanced NSCLC, and $30 \%$ of patients with advanced NSCLC will experience progression with platinumbased first-line treatment. We found that the Shh pathway was activated in advanced NSCLC, and that the expression of Gli2 was associated with chemoresistance. A Gli2-positive score was found to be an independent factor of poor PFS and poor OS in multivariate analysis. In vitro studies confirmed that the inhibition of the Shh pathway had a synergistic effect with cisplatin on proliferation inhibition, especially in the most chemoresistant cells. These results support the developpement of clinical trials testing Shh-targeted therapies in chemoresistant advanced NSCLC.

\section{Aknowledgements:}


Source of support: Fonds de Recherche en Santé Respiratoire (EGL, TV), Legs Poix 2013 Chancellerie des Universités de Paris, Fondation du Souffle et du Fonds de Dotation "Recherche en Santé Respiratoire" SR2014-021.

Conflict of interest: none 


\section{References}

1. Crinò L, Scagliotti GV, Ricci S, et al. Gemcitabine and cisplatin versus mitomycin, ifosfamide, and cisplatin in advanced non-small-cell lung cancer: a randomized phase III study of the Italian Lung Cancer Project. J Clin Oncol. 1999;17:3522-30.

2. Kelly K, Crowley J, Bunn PA Jr, et al. Randomized phase III trial of paclitaxel plus carboplatin versus vinorelbine plus cisplatin in the treatment of patients with advanced non-small cell lung cancer: a Southwest Oncology Group trial. J Clin Oncol. 2001;19:3210-8.

3. Rosell R, Gatzemeier U, Betticher DC, et al. Phase III randomised trial comparing paclitaxel/carboplatin with paclitaxel/cisplatin in patients with advanced non-small-cell lung cancer: a cooperative multinational trial. Ann Oncol. 2002;13:1539-49.

4. Scagliotti GV, De Marinis F, Rinaldi M, et al. Phase III randomized trial comparing three platinum-based doublets in advanced non-small-cell lung cancer. J Clin Oncol. 2002;20:4285-91.

5. Schiller JH, Harrington D, Belani CP, et al. Comparison of four chemotherapy regimens for advanced non-small-cell lung cancer. $\mathrm{N}$ Engl $\mathrm{J}$ Med. 2002;346:92-8.

6. Smit EF, van Meerbeeck JPAM, Lianes P, et al. Three-arm randomized study of two cisplatin-based regimens and paclitaxel plus gemcitabine in advanced non-small-cell lung cancer: a phase III trial of the European Organization for Research and Treatment of Cancer Lung Cancer Group-EORTC 08975. J Clin Oncol. 2003;21:3909-17. 
7. Gridelli C, Gallo C, Shepherd FA, et al. Gemcitabine plus vinorelbine compared with cisplatin plus vinorelbine or cisplatin plus gemcitabine for advanced non-small-cell lung cancer: a phase III trial of the Italian GEMVIN Investigators and the National Cancer Institute of Canada Clinical Trials Group. J Clin Oncol. 2003;21:3025-34.

8. Fossella F, Pereira JR, von Pawel J, et al. Randomized, multinational, phase III study of docetaxel plus platinum combinations versus vinorelbine plus cisplatin for advanced non-small-cell lung cancer: the TAX 326 study group. J Clin Oncol. 2003;21:3016-24.

9. Georgoulias V, Ardavanis A, Agelidou A, et al. Docetaxel versus docetaxel plus cisplatin as front-line treatment of patients with advanced non-small-cell lung cancer: a randomized, multicenter phase III trial. J Clin Oncol. 2004;22:2602-9.

10. Giroux Leprieur E, Antoine M, Vieira T, et al. Clinical and molecular features in patients with advanced non-small cell lung carcinoma refractory to first-line platinum-based chemotherapy. Lung Cancer. 2013;79:167-172.

11. Vieira T, Girard N, Ung M, et al. Efficacy of first-line chemotherapy in patients with advanced lung sarcomatoid carcinoma. J Thorac Oncol. 2013;8:1574-7.

12. Olaussen KA, Dunant A, Fouret $P$, et al. DNA repair by ERCC1 in non-smallcell lung cancer and cisplatin-based adjuvant chemotherapy. N Engl J Med. 2006;355:983-91.

13. Papadaki C, Sfakianaki M, loannidis $G$ et al. ERCC1 and BRAC1 mRNA expression levels in the primary tumor could predict the effectiveness of the second-line cisplatin-based chemotherapy in pretreated patients with metastatic non-small cell lung cancer. J Thorac Oncol. 2012;7:663-71. 
14. Lee SH, Noh KB, Lee JS, et al. Thymidylate synthase and ERCC1 as predictive markers in patients with pulmonary adenocarcinoma treated with pemetrexed and cisplatin. Lung Cancer. 2013;81:102-8.

15. Wislez M, Barlesi F, Besse B, et al. Customized adjuvant phase II trial in patients with non-small-cell lung cancer: IFCT-0801 TASTE. J Clin Oncol. $2014 ; 32: 1256-61$.

16. Friboulet L, Olaussen KA, Pignon JP, et al. ERCC1 isoform expression and DNA repair in non-small-cell lung cancer. N Engl J Med. 2013;368:1101-10.

17. Rosell R, Perez-Roca L, Sanchez JJ, et al. Customized treatment in nonsmall-cell lung cancer based on EGFR mutations and BRCA1 mRNA expression. PLoS One. 2009;4:e5133.

18. Pierceall WE, Olaussen KA, Rousseau V, et al. Cisplatin benefit is predicted by immunohistochemical analysis of DNA repair proteins in squamous cell carcinoma but not adenocarcinoma: theranostic modeling by NSCLC constituent histological subclasses. Ann Oncol. 2012;23:2245-52.

19. Massuti B, Cobo M, Rodriguez-Paniagua JM, et al. Randomized phase III trial of customized adjuvant chemotherapy (CT) according BRCA-1 expression levels in patients with node positive resected non-small cell lung cancer (NSCLS) SCAT: A Spanish Lung Cancer Group trial (Eudract:2007-00006715; NCTgov: 00478699). J Clin Oncol. 2015:33(suppl):abstr7507.

20. Perona R, López-Ayllón BD, de Castro Carpeño J, Belda-Iniesta C. A role for cancer stem cells in drug resistance and metastasis in non-small-cell lung cancer. Clin Transl Oncol. 2011;13:289-93. 
21. Watkins DN, Berman DM, Burkholder SG, Wang B, Beachy PA, Baylin SB. Hedgehog signalling within airway epithelial progenitors and in small-cell lung cancer. Nature. 2003;422:313-7.

22. Park KS, Martelotto LG, Peifer M, et al. A crucial requirement for Hedgehog signaling in small cell lung cancer. Nat Med. 2011;17:1504-8.

23. Yuan Z, Goetz JA, Singh S, et al. Frequent requirement of hedgehog signaling in non-small cell lung carcinoma. Oncogene. 2007;26:1046-55.

24. Gialmanidis IP, Bravou V, Amanetopoulou SG, Varakis J, Kourea H, Papadaki H. Overexpression of hedgehog pathway molecules and FOXM1 in non-small cell lung carcinomas. Lung Cancer. 2009;66:64-74.

25. Raz G, Allen KE, Kingsley C, et al. Hedgehog signaling pathway molecules and ALDH1A1 expression in early-stage non-small cell lung cancer. Lung Cancer. 2012;76:191-6.

26. Travis WD, Brambilla E, Noguchi M, et al. International association for the study of lung cancer/american thoracic society/european respiratory society international multidisciplinary classification of lung adenocarcinoma. J Thorac Oncol. 2011;6:244-85.

27. Wang YF, Chang CJ, Lin CP, et al. Expression of hedgehog signaling molecules as a prognostic indicator of oral squamous cell carcinoma. Head Neck. 2012;34:1556-61.

28. Jokoji R, Yamasaki T, Minami S, et al. Combination of morphological feature analysis and immunohistochemistry is useful for screening of EML4-ALKpositive lung adenocarcinoma. J Clin Pathol. 2010;63:1066-70. 
29. Yi ES, Boland JM, Maleszewski JJ, et al. Correlation of IHC and FISH for ALK gene rearrangement in non-small cell lung carcinoma: IHC score algorithm for FISH. J Thorac Oncol. 2011;6:459-65.

30. Chou TC. Drug combination studies and their synergy quantification using the Chou-Talalay method. Cancer Res. 2010;70:440-6.

31. Huang L, Walter V, Hayes DN, Onaitis M. Hedgehog-GLI Signaling Inhibition Suppresses Tumor Growth in Squamous Lung Cancer. Clin Cancer Res. 2014;20:1566-75.

32. Sims-Mourtada J, Izzo JG, Ajani J, Chao KS. Sonic Hedgehog promotes multiple drug resistance by regulation of drug transport. Oncogene. 2007;26:5674-9.

33. Tian F, Schrödl K, Kiefl R, Huber RM, Bergner A. The hedgehog pathway inhibitor GDC-0449 alters intracellular Ca2+ homeostasis and inhibits cell growth in cisplatin-resistant lung cancer cells. Anticancer Res. 2012;32:89-94.

34. Ahmad A, Maitah MY, Ginnebaugh KR, et al. Inhibition of Hedgehog signaling sensitizes NSCLC cells to standard therapies through modulation of EMTregulating miRNAs. J Hematol Oncol. 2013;6:77.

35. Yue D, Li H, Che J, et al. Hedgehog/Gli promotes epithelial-mesenchymal transition in lung squamous cell carcinomas. J Exp Clin Cancer Res. 2014;33:34.

36. Agren M, Kogerman P, Kleman MI, Wessling M, Toftgård R. Expression of the PTCH1 tumor suppressor gene is regulated by alternative promoters and a single functional Gli-binding site. Gene. 2004;330:101-14. 
37.Ikram MS, Neill GW, Regl G, et al. Gli2 is expressed in normal human epidermidis and BCC and induces Gli1 expression by binding to its promoter. J Invest Dermatol. 2004;122:1503-29.

38. Lipinski RJ, Gipp JJ, Zhang J, Doles JD, Bushman W. Unique and complimentary activities of the Gli transcription factors in Hedgehog signaling. Exp Cell Res. 2006;312:1925-38.

39. Tian F, Mysliwietz J, Ellwart J, Gamarra F, Huber RM, Bergner A. Effects of the Hedgehog pathway inhibitor GDC-0449 on lung cancer cell lines are mediated by side populations. Clin Exp Med. 2012;12:25-30.

40. Li H, Lui N, Cheng T, et al. Gli as a Novel Therapeutic Target in Malignant Pleural Mesothelioma. PlosOne. 2013;8:e57346.

41.Belani CK, Dahlberg SE, Rudin CM, et al. Three-arm randomized phase II study of cisplatin and etoposide (CE) versus CE with either vismodegib (V) or cixutumumab (Cx) for patients with extensive stage-small cell lung cancer (ESSCLC) (ECOG 1508). J Clin Oncol. 2013;31suppl:abstr 7508. 
Table1: Demographic, pathological, and molecular characteristics of patients

\begin{tabular}{|c|c|c|c|c|}
\hline & Total $(n=36)$ & $\begin{array}{l}\text { r-patients } \\
(n=12)\end{array}$ & $\begin{array}{l}\text { C-patients } \\
(n=24)\end{array}$ & p-value** \\
\hline$\overline{\text { Age (mean } \pm S D)}$ & $53.4( \pm 10.2)$ & $53.4( \pm 8.1)$ & $54.8( \pm 11.3)$ & 0.72 \\
\hline Gender (male) & $23(63.9)$ & $4(33.3)$ & $19(79.2)$ & 0.01 \\
\hline Stage (IV) & $23(63.9)$ & $9(75.0)$ & $14(58.3)$ & 0.33 \\
\hline Smoker status (N/FS/CS) & $\begin{array}{l}3 / 9 / 23 \\
(8.6 / 25.7 / 65.7)\end{array}$ & $\begin{array}{l}1 / 3 / 7 \\
(9.1 / 27.3 / 63.6)\end{array}$ & $\begin{array}{l}2 / 5 / 16 \\
(8.3 / 25.0 / 66.7)\end{array}$ & 0.93 \\
\hline Histology & & & & 0.21 \\
\hline Adenocarcinoma & $24(66.7)$ & $7(58.3)$ & $17(70.8)$ & \\
\hline Squamous cell carcinoma & $4(11.1)$ & $2(16.7)$ & $3(12.5)$ & \\
\hline Large cell carcinoma & $4(11.2)$ & $1(9.1)$ & $2(8.3)$ & \\
\hline Sarcomatoid carcinoma & $2(5.6)$ & $2(16.7)$ & $0(0.0)$ & \\
\hline Other & $2(5.6)$ & $0(0.0)$ & $2(8.4)$ & \\
\hline $\begin{array}{l}\text { Drug associated } \\
\text { platinum }\end{array}$ & & & & 0.48 \\
\hline Gemcitabine & $21(58.3)$ & $6(50.0)$ & $15(62.5)$ & \\
\hline Taxane & $12(33.3)$ & $4(33.3)$ & $8(33.3)$ & \\
\hline Etoposide & $2(5.6)$ & $1(9.1)$ & $1(4.2)$ & \\
\hline Ifosamide - etoposide & $1(2.8)$ & $1(9.1)$ & $0(0.0)$ & \\
\hline \multicolumn{5}{|l|}{ Molecular abnormalities ${ }^{*}$} \\
\hline KRAS mutation & $2(6.9)$ & $2(20.0)$ & $0(0.0)$ & 0.21 \\
\hline EGFR mutation & $4(15.4)$ & $1(11.1)$ & $3(17.6)$ & 0.89 \\
\hline ALK translocation & $2(5.9)$ & $1(8.3)$ & $1(4.5)$ & 0.75 \\
\hline
\end{tabular}

r-patients: refractory patients; c-patients: controlled patients; N: never smoker; FS: former smoker; CS: current smoker; SD: standard deviation; KRAS: Kirsten Ras; EGFR: epidermal growth factor receptor; ALK: anaplastic lymphoma kinase. * percentages are expressed according to amplified samples. ${ }^{* *} p$-value using chisquared test or Mann-Whitney test 
Table2: Comparison of Gli2-positive tumors and Gli2-negative tumors

\begin{tabular}{|c|c|c|c|}
\hline & $\begin{array}{l}\text { GLI2 pos. } \\
(n=7)\end{array}$ & $\begin{array}{l}\text { Gli2 neg. } \\
(n=29)\end{array}$ & $p$-value ${ }^{\star \star}$ \\
\hline Age (mean $\pm S D)$ & $50.6( \pm 5.6)$ & $55.2( \pm 11.0)$ & 0.29 \\
\hline Gender(male) & $3(42.9)$ & $20(69.0)$ & 0.20 \\
\hline Smoker status (N/FS/CS) & $0 / 2 / 5$ & $3 / 8 / 18$ & 0.67 \\
\hline Stage IV & $6(85.7)$ & $12(41.4)$ & 0.04 \\
\hline Histology & & & 0.34 \\
\hline Adenocarcinoma & $3(42.9)$ & $19(65.5)$ & \\
\hline Squamous cell carcinoma & $2(28.6)$ & $4(13.8)$ & \\
\hline Large cell carcinoma & $2(28.6)$ & $2(6.8)$ & \\
\hline Sarcomatoid carcinoma & $0(0.0)$ & $2(6.9)$ & \\
\hline Other & $0(0.0)$ & $2(6.9)$ & \\
\hline Drug associated with platinum & 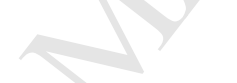 & & 0.24 \\
\hline Gemcitabine & $2(28.6)$ & $19(65.5)$ & \\
\hline Taxane & $4(57.1)$ & $8(27.6)$ & \\
\hline Etoposide & $1(14.3)$ & $1(3.4)$ & \\
\hline Ifosamide - etoposide & $0(0.0)$ & $1(3.4)$ & \\
\hline \multicolumn{4}{|l|}{ Molecular abnormalities* } \\
\hline KRAS mutation & $1(14.3)$ & $1(5.6)$ & 0.92 \\
\hline EGFR mutation & $0(0.0)$ & $4(19.0)$ & 0.71 \\
\hline ALK translocation & $1(14.3)$ & $1(3.6)$ & 0.86 \\
\hline
\end{tabular}

Pos.: positive; Neg.: negative; N: never smoker; FS: former smoker; CS: current smoker; SD: standard deviation; KRAS: Kirsten Ras; EGFR: epidermal growth factor receptor; ALK: anaplastic lymphoma kinase. "percentages are expressed according to amplified samples. ${ }^{* *} p$-value using chi-squared test or Mann-Whitney test 
ACCEPTED MANUSCRIPT

Table 3: Multivariate analysis on progression-free survival (PFS)

\begin{tabular}{lllll}
\hline Variable & p-value & HR & $\mathbf{2 5 \%} \mathbf{C l}$ & $\mathbf{9 5 \%} \mathbf{C l}$ \\
\hline Sarcomatoid subtype & 0.004 & 14.28 & 2.29 & 83.33 \\
Gli2-positive score & 0.04 & 2.64 & 1.05 & 6.63 \\
KRAS mutation & 0.27 & 2.87 & 0.44 & 18.52 \\
Gender & 0.85 & 1.08 & 0.46 & 2.52
\end{tabular}

P-value using Cox model; Cl: confidence interval; KRAS: Kirsten Ras; HR: hazard ratio

Table 4: Multivariate analysis on overall survival (OS)

\begin{tabular}{lllll}
\hline Variable & p-value & HR & 25\% Cl & 95\% Cl \\
\hline Gli2-positive score & 0.003 & 4.36 & 1.67 & 11.36 \\
Gender & 0.23 & 0.58 & 0.24 & 1.41 \\
KRAS mutation & 0.44 & 2.00 & 0.34 & 11.76 \\
Sarcomatoid subtype & 0.64 & 1.68 & 0.19 & 14.49 \\
P-value using Cox model; Cl: confidence interval; HR: hazard ratio; KRAS: Kirsten & &
\end{tabular}




\section{Figure caption}

Figure 1: R-patients more often exhibited Gli2-positive score than c-patients

A: Example of a Gli2-negative tumor (x200). B: Example of a Gli2-positive tumor (x200). C: Proportion of r-patients (refractory patients) and c-patients (controlleddisease patients) with Gli1-positive score. P-value by chi-squared test. D: Proportion of r-patients and c-patients with Gli2-positive score. P-value by chi-squared test

Figure 2: Gli2-positive score was associated with shorter progression-free survival (PFS) and overall survival (OS)

A-B: Performance-free survival (PFS). C-D: Overall survival (OS). A and C: Gli1 score. B and D: Gli2 score. P-values were calculated with log-rank test

Figure 3: Synergistic effects of vismodegib with cisplatin

A: Cells were treated with vismodegib, cisplatin, and combination (cisplatin + vismodegib) at the concentrations $(\mu \mathrm{M})$ indicated in the figure. Cell proliferation was measured by WST-1 assay on Day 2 of the drug course. The combinatorial effects were further quantified by the Chou-Talalay method to obtain the Combination Index $(\mathrm{Cl})$, where $\mathrm{Cl}<1,=1$, and $>1$ represented synergism, additive, and antagonism effects, respectively. B: Correlation between the IC50 of cisplatin of the different cell lines and the $\mathrm{Cl}$. P-value was calculated with Spearman's rank-order correlation test 
Figure 1

A

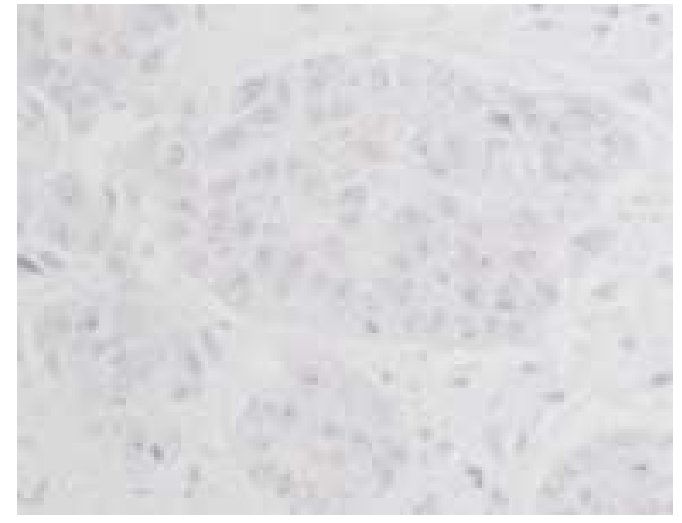

B

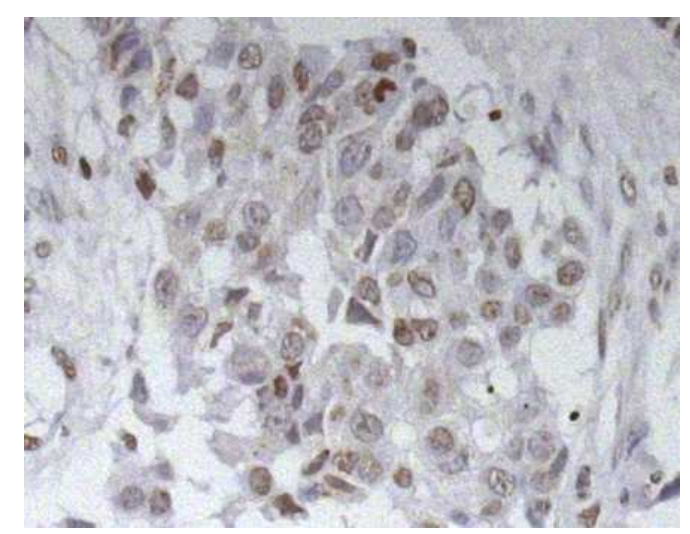

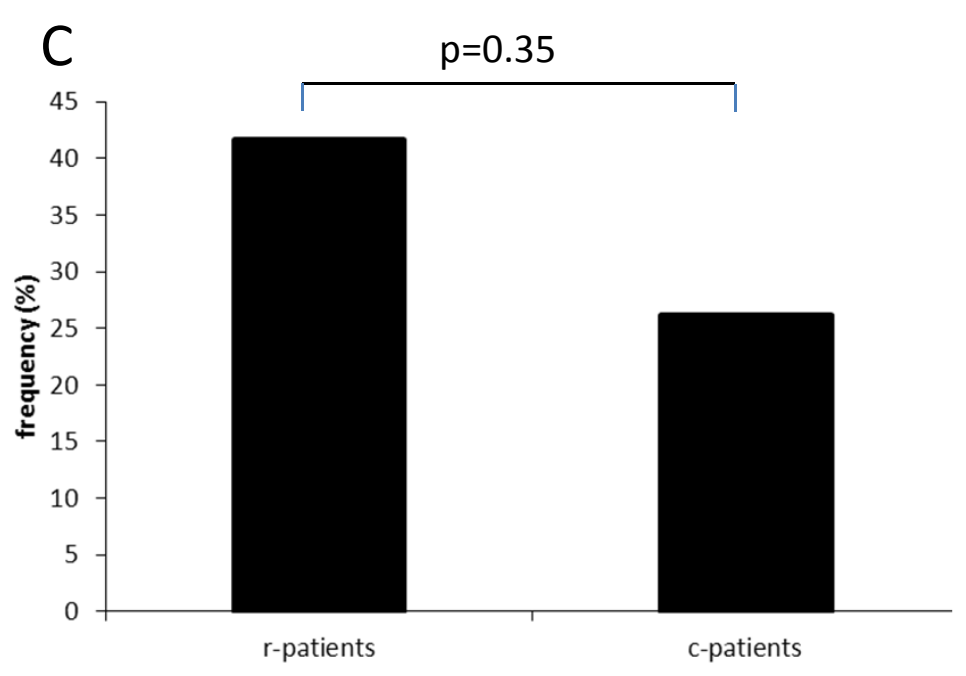

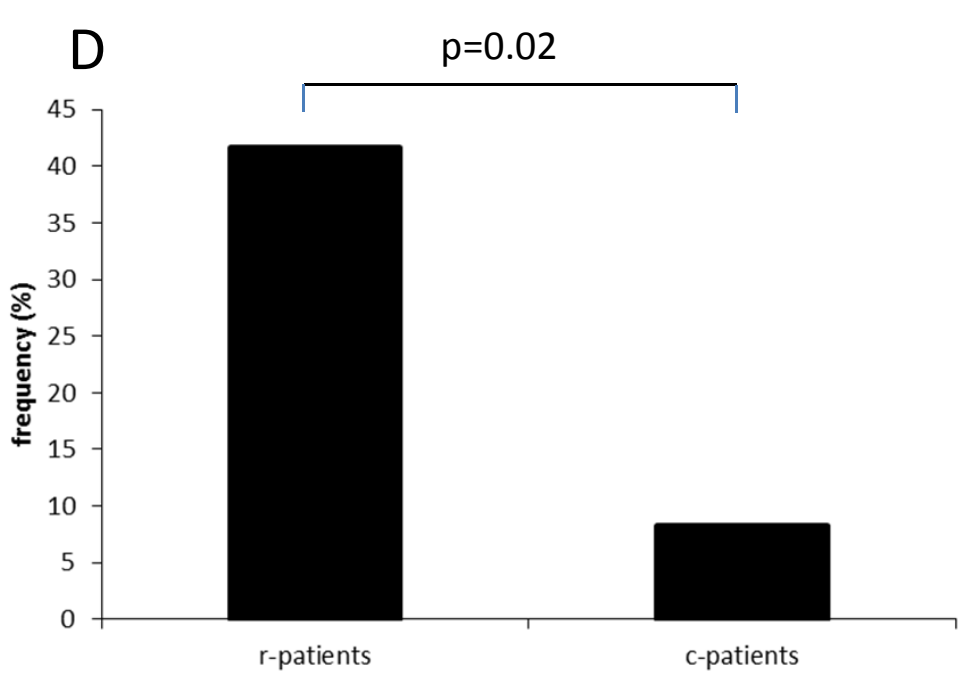




\section{Figure 2}

A

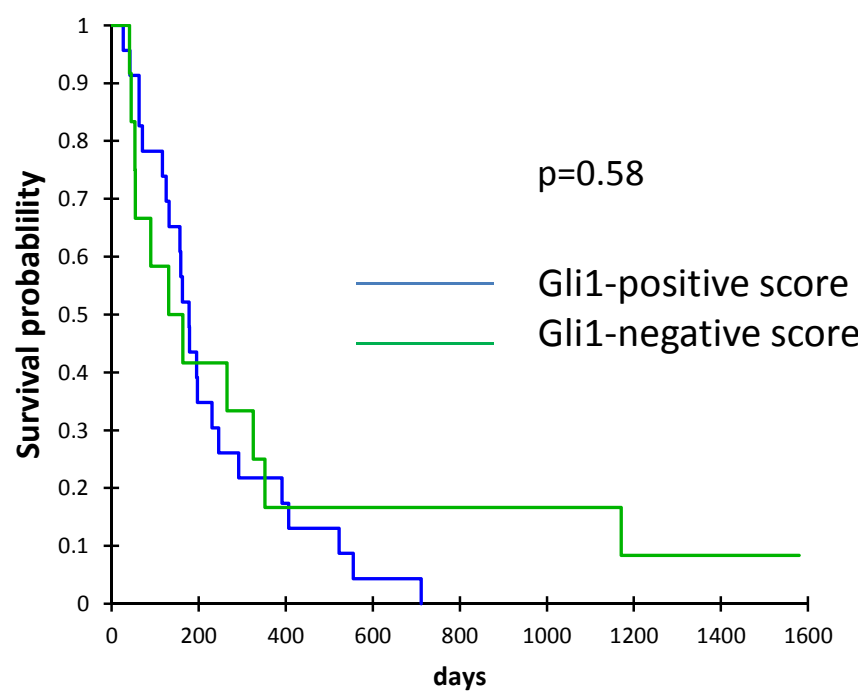

C

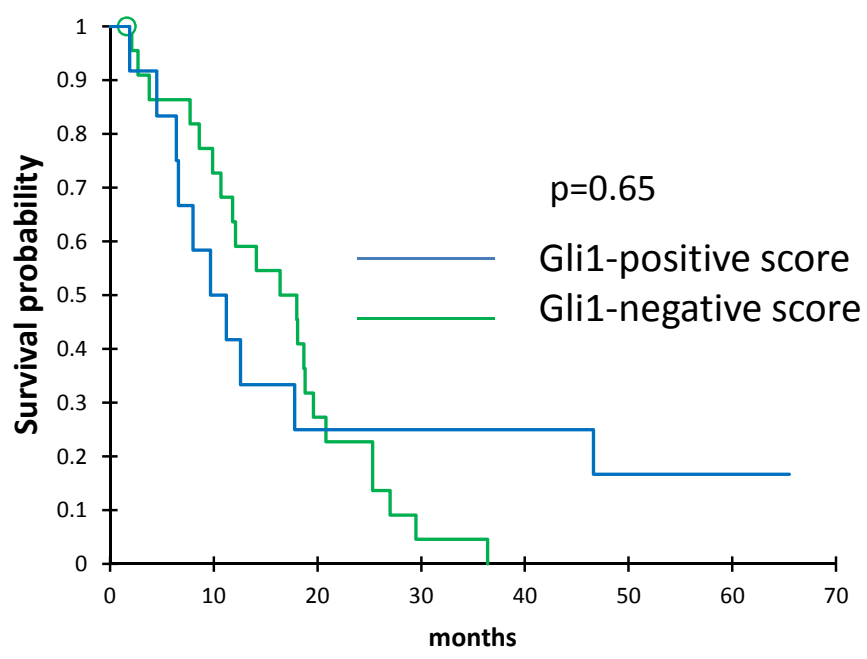

B
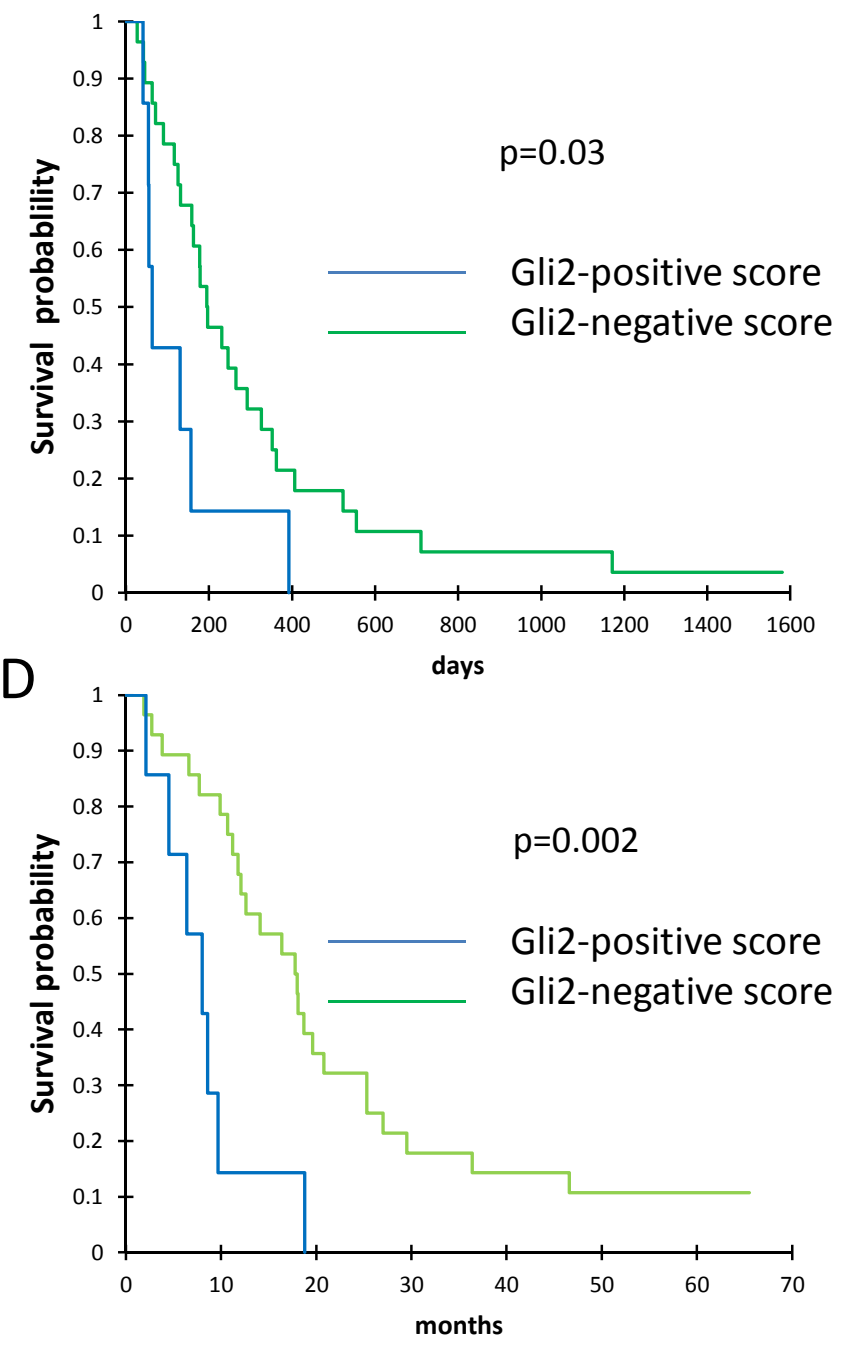
Figure 3

A

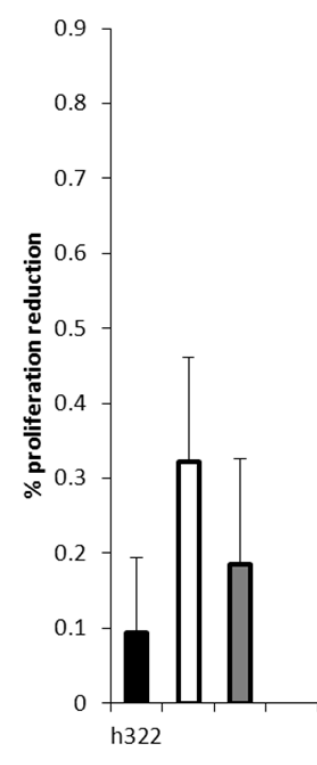

Cisplatin

Vismodegib $\begin{array}{lll}20 & 0 & 20\end{array}$

C.I.

Effect
2.39

$\begin{array}{ll}2.39 & 1.49\end{array}$

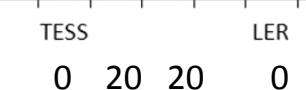

LER

$\begin{array}{lll}20 & 0 & 20\end{array}$

1.16

$\begin{array}{lll}0 & 20 & 20\end{array}$

$\begin{array}{ccc}20 & 0 \quad 20 \\ 0.82\end{array}$

antagonistic synergistic
B

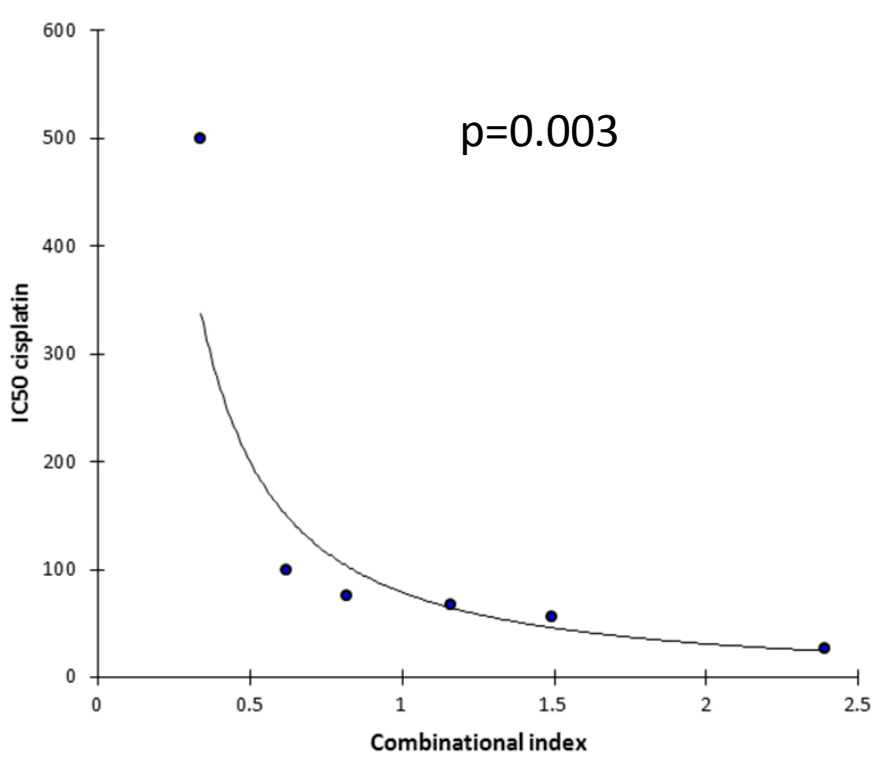

